\title{
Możliwości wykorzystania substratu jonitowego i archebakterii do wspomagania rozwoju roślin na gruntach jałowych
}

\author{
Mariola Chomezyńska ${ }^{1}$, Vladimir Soldatov ${ }^{2}$ \\ ${ }^{1}$ Wydziat Inżynierii Środowiska, Politechnika Lubelska, \\ e-mail:m.chomczynska@wis.pol.lublin.pl \\ ${ }^{2}$ Instytut Chemii Fizycznej i Organicznej, Białoruska Narodowa Akademia Nauk, \\ e-mail:Soldatov@ifoch.bas-net.by
}

\begin{abstract}
Streszczenie: Przeprowadzone badania dotyczyły określenia możliwości wykorzystania substratu jonitowego i archebakterii do wspomagania rozwoju roślin na gruntach jałowych (np. na nasypach dróg, skarpach mostów itp.). Realizacja badań wymagała przeprowadzenia doświadczenia wazonowego z kupkówką pospolitą jako gatunkiem testowym. Na potrzeby eksperymentu przygotowano dwie podstawowe serie podłoży: serię kontrolną piasek (model jałowego gruntu) i serię stanowiącą mieszaninę piasku i 2\% (objętościowo) dodatku substratu jonitowego (nośnik pierwiastków odżywczych roślin). W trakcie wegetacji roślin połowę liczby wazonów serii kontrolnej podlewano wodą wodociągową, natomiast drugą połowę podlewano wodą wodociągową wzbogaconą $\mathrm{w}$ archebakterie pochodzące z preparatu komercyjnego Arkea ${ }^{\circledR}$ firmy Archaea Solutions ${ }^{\mathrm{TM}}$. Analogicznie postąpiono $\mathrm{z}$ wazonami zawierającymi mieszaninę piasku $\mathrm{z}$ dodatkiem substratu jonitowego. Po zakończeniu doświadczenia stwierdzono, że dodatek substratu jonitowego do piasku korzystnie wpłynął na proces wzrostu i rozwoju roślin istotnie zwiększając wartości parametrów wegetacyjnych. Wbrew oczekiwaniom nie zaobserwowano pozytywnego oddziaływania drobnoustrojów z domeny Archeae na proces wegetacji gatunku testowego. Dodatek substratu jonitowego można polecić jako materiał wspomagający rozwój pokrywy roślinnej na terenach zdegradowanych i obiektach infrastruktury drogowej.
\end{abstract}

Słowa kluczowe: substraty jonitowe, archebakterie, infrastruktura drogowa

\section{Wprowadzenie}

Istnieje potrzeba wspomagania rozwoju szaty roślinnej na obiektach infrastruktury drogowej. Roślinność pełni tu funkcje techniczne (stabilizacja powierzchni nasypów, zabezpieczenia skarp przed rozmyciami podczas deszczów nawalnych), odgrywa rolę środowiskową i decyduje o walorach estetycznych. Z punktu widzenia inżynierii drogowej kluczowym problemem jest zapewnienie szybkiego rozwoju roślin z dobrze rozwiniętymi systemami korzeniowymi. W tym kontekście aplikacyjnym konieczne wydają się badania z wykorzystaniem syntetycznych wymieniaczy jonowych (jonitów). Jonity są polimerami o właściwościach jonowymiennych, które od wielu lat znajdują szerokie zastosowanie w oczyszczaniu wody głównie w procesach zmiękczania i demineralizacji. W pierwszej połowie ubiegło wieku pojawiła się również idea wykorzystania jonitów jako nośników pierwiastków odżywczych dla roślin [1]. Pomysł ten był stale rozwijany przez zespół badawczy z Białoruskiej Narodowej Akademii Nauk w Mińsku, co ostatecznie doprowadzi- 
ło do przygotowania substratów jonitowych o nazwie handlowej Biona ${ }^{\circledR}$. Poszczególne rodzaje substratów jonitowych są mieszaninami kationitów i anionitów nasyconych w stosownych proporcjach jonami makro- i mikroelementów [2,3]. Wyniki wielu testów wykazały, że substraty jonitowe są doskonałymi podłożami umożliwiającymi uprawę roślin w zamkniętych ekologicznych systemach takich jak statki kosmiczne, stacje arktyczne czy okręty podwodne. Pozytywne rezultaty tych badań zainicjowały nową serię doświadczeń w Politechnice Lubelskiej nad wykorzystaniem substratów jonitowych w biologicznej rekultywacji gleb. W ich wyniku stwierdzono m.in., że dawka substratu jonitowego w ilości $1-2 \%$ obj. jest wystarczająca dla potrzeb nawożenia ubogich piaszczystych gleb [4]. $\mathrm{Z}$ uwagi na swoje właściwości substraty jonitowe można również polecić jako materiały intensyfikujące rozwój pokrywy roślinnej stabilizującej pobocza dróg czy skarpy mostów. W prezentowanym artykule przedstawiono badania, których celem było określenie jednoczesnego wpływu substratu jonitowego i drobnoustrojów z domeny Archeae na przebieg wegetacji roślin. Badania te podjęto, aby przekonać się czy warto wspólnie stosować substraty jonitowe i archebakterie do poprawy właściwości gruntów, mając na uwadze doniesienia mówiące o możliwym pozytywnym oddziaływaniu tych mikroorganizmów na niektóre gatunki roślin.

\section{Material i metody}

Do badań jako podstawowe materiały wykorzystano: piasek, substrat jonitowy oraz preparat Arkea ${ }^{\circledR}$. Piasek pozyskano w kopalni w Gołębiu/k. Puław (woj. lubelskie). Wartość $\mathrm{pH}$ piasku $\mathrm{w}_{2} \mathrm{O}_{\text {dest. }}$ wynosiła 6,01 . Skład granulometryczny piasku oznaczony metodą dyfrakcji laserowej $[5,6]$, przedstawiał się następująco: frakcja ziaren o średnicy 2-1 mm $0 \%$; 1-0,5 mm - 17,3\%; frakcja 0,5-0,25 mm - 54,3\%; frakcja 0,25-0,1 mm - 27,7\%, frakcja 0,1-0,05 mm-0,06\%, frakcja poniżej 0,05 mm-0,3\%. Zawartości makro- i mikroelementów w piasku podano w tabeli 1. Zasobność piasku w przyswajalne maro - i mikro-

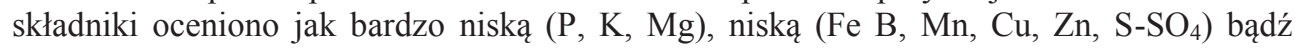
niedostateczną dla roślin $\left(\mathrm{Ca}, \mathrm{N}_{-} \mathrm{NO}_{3}, \mathrm{~N}-\mathrm{NH}_{4}\right)$ na podstawie odpowiednich norm [7-14] i danych literaturowych [15-17].

Tabela 1. Zawartości makroelementów i mikroelementów w piasku użytym do doświadczania wegetacyjnego

\begin{tabular}{|c|c|c|c|c|c|c|}
\hline \multirow[t]{2}{*}{ Forma } & \multicolumn{6}{|c|}{ Makroelementy $[\mathrm{mg} / 100 \mathrm{~g}]$} \\
\hline & $\mathrm{N}$ & $\mathrm{P}$ & $\mathrm{K}$ & $\mathrm{Ca}$ & $\mathrm{Mg}$ & $\mathrm{S}$ \\
\hline Ekstrahowalna & $0,014 \mathrm{~N}^{-\mathrm{NO}_{3}}$ & 0,20 & 0,19 & 0,204 & 0,065 & $0,093 \mathrm{~S}-$ \\
\hline $\mathrm{H}_{2} \mathrm{O}$ dest. & $0,049 \mathrm{~N}^{-\mathrm{NH}_{4}}$ & & & & & $\mathrm{SO}_{4}$ \\
\hline \multirow[t]{4}{*}{ Przyswajalna } & $<0,128 \mathrm{~N}-\mathrm{NO}_{3}{ }^{\mathrm{a}}$ & $0,48 \mathrm{P}^{\mathrm{b}}$ & $<1,99 \mathrm{~K}^{\mathrm{b}}$ & $4,41^{\mathrm{c}}$ & $1,0^{\mathrm{d}}$ & $0,53 \mathrm{~S}-$ \\
\hline & $0,198 \mathrm{~N}^{-\mathrm{NH}_{4}}{ }^{\mathrm{a}}$ & $\left(1,1 \mathrm{P}_{2} \mathrm{O}_{5}\right)$ & $\left(<2,4 \mathrm{~K}_{2} \mathrm{O}\right)$ & & & $\mathrm{SO}_{4}{ }^{\mathrm{e}}$ \\
\hline & \multicolumn{6}{|c|}{ Mikroelementy [mg/kg] } \\
\hline & $\mathrm{Cu}$ & $\mathrm{Fe}$ & $\mathrm{Mn}$ & $\mathrm{Zn}$ & $\mathrm{B}$ & Mo \\
\hline Przyswajalna $^{\mathrm{f}}$ & 0,046 & 27,24 & 0,768 & 0,092 & $<0,384$ & $<0,028$ \\
\hline
\end{tabular}

Objaśnienia: ${ }^{\mathrm{a}}$ - zawartość po ekstrakcji $1 \% \mathrm{~K}_{2} \mathrm{SO}_{4},{ }^{\mathrm{b}}$ - zawartość po ekstrakcji $0,04 \mathrm{M}\left(\mathrm{CH}_{3} \mathrm{CHOHCOO}\right)_{2} \mathrm{Ca}$, ${ }^{\mathrm{c}}$ - zawartość po ekstrakcji $0,03 \mathrm{M} \mathrm{CH}_{3} \mathrm{COOH},{ }^{\mathrm{d}}$ - zawartość po ekstrakcji $0,0125 \mathrm{M} \mathrm{CaCl}_{2},{ }^{\mathrm{e}}$ - zawartość po ekstrakcji $0,5 \mathrm{M} \mathrm{CH}_{3} \mathrm{COOH}+0,25 \mathrm{M} \mathrm{CH}_{3} \mathrm{COONH}_{4},{ }^{\mathrm{f}}$ - zawartość po ekstrakcji $1 \mathrm{M} \mathrm{HCl}$, zawartość przyswajalnego fosforu i potasu przeliczono na odpowiednie tlenki ponieważ ocenę zasobności gleb opracowano z uwzględnieniem tych związków. 
Wykorzystany w badaniach substrat jonitowy przygotowano na bazie sześciu form monojonowych to jest: azotanowej, fosforanowej, siarczanowej, potasowej, magnezowej i wapniowej. Formy te otrzymano stosując kationit silnie kwaśny KU-2 oraz anionit polifunkcyjny EDE-10P - oba jonity wyprodukowano w firmie Uralkhimplast, Ural Chemical Company (Federacja Rosyjska). Zasobność substratu jonitowego w jony makroskładników przedstawiono w tabeli 2.

Preparat Arkea ${ }^{\circledR}$ otrzymano od przedsiębiorstwa Soltech będącego polskim przedstawicielem firmy Archeae Solutions Inc. (USA). Preparat ten był źródłem drobnoustrojów z domeny Archeae. Skład preparatu ze względu na liczbę i rodzaj szczepów chroniony jest prawem patentowym.

Tabela 2. Zawartości jonów makroelementów w substracie jonitowym [mval/100g]

\begin{tabular}{cccccc}
\hline $\mathrm{NO}_{3}{ }^{-}$ & $\mathrm{H}_{2} \mathrm{PO}_{4}^{-}$ & $\mathrm{SO}_{4}{ }^{2-}$ & $\mathrm{Ca}^{2+}$ & $\mathrm{Mg}^{2+}$ & $\mathrm{K}^{+}$ \\
\hline 23,64 & 23,64 & 108,31 & 183,86 & 32,98 & 18,84 \\
\hline
\end{tabular}

Dla osiągnięcia celu badań przeprowadzono eksperyment wazonowy z kupkówką pospolitą (Dactylis glomerata L.) jako gatunkiem testowym. Na potrzeby eksperymentu przygotowano dwie podstawowe serie podłoży: serię kontrolną (piasek) i serię stanowiącą mieszaninę piasku i 2\% (objętościowo) dodatku substratu jonitowego. Połowę doniczek serii kontrolnej podlano wodą wodociągową natomiast drugą połowę podlano wodą wodociągową wzbogaconą w archebakterie pochodzące z preparatu Arkea ${ }^{\circledR}$. Analogicznie postąpiono $\mathrm{z}$ doniczkami zawierającymi mieszaninę piasku $\mathrm{z}$ dodatkiem substratu (tabela 3 ). Następnie do poszczególnych doniczek serii doświadczenia wysiano po 50 nasion kupkówki pospolitej. Po 8 dniach od momentu wysiewu nasion, liczbę roślin ujednolicono do 28 . Doświadczenie prowadzono $\mathrm{w}$ fitotronie, $\mathrm{z}$ fotoperiodem $13 / 11 \mathrm{~h}$ (dzień/noc) i natężeniem światła na poziomie 11000 lx. Temperatura dzienna w pomieszczeniu wynosiła $25^{\circ} \mathrm{C}$, a temperaturę nocną utrzymywano na poziomie $16^{\circ} \mathrm{C}$. W trakcie wegetacji rośliny podlewano odpowiednio: wodą wodociągową i wodą zawierającą archebakterie. Obecność drobnoustrojów w wodzie kontrolowano poprzez oznaczanie zawartości całkowitej suchej masy SM i zawartości suchej masy organicznej - SMO. Średnie wartości tych parametrów w czasie trwania doświadczenia wyniosły: $456,1 \mathrm{mg} / \mathrm{dm}^{3}$ (SM) i $35,6 \mathrm{mg} / \mathrm{dm}^{3}$ (SMO).

Eksperyment zakończono w 42 dniu wegetacji. Pędy nadziemne roślin ścięto a korzenie wyizolowano z podłoży. Świeżą i suchą $\left(105^{\circ} \mathrm{C}\right)$ biomasę pędów nadziemnych i korzeni określono metodą wagową. Otrzymane wyniki posłużyły do obliczenia średnich wartości parametrów charakteryzujących proces wzrostu i rozwoju roślin w poszczególnych seriach eksperymentu (średnie arytmetyczne). Dla określenia istotności różnic między porównywanymi średnimi zastosowano test t-Studenta $(\alpha=0,05)$. W sytuacji, gdy test F Fishera-Snedecora nie pozwalał na zastosowanie testu t-Studenta (brak zachowania warunku równości wariancji) w celu określenia istotności różnic między średnimi użyto testu v Aspin-Welcha $[18,19]$.

Tabela 3. Charakterystyka serii podłoży doświadczenia wegetacyjnego

\begin{tabular}{lcccc}
\hline Seria & P & PA & P+S & P+SA \\
\hline Ilość piasku $[\mathrm{ml}]$ & 300 & 300 & 294 & 294 \\
\hline Ilość substratu $[\mathrm{ml}]$ & - & - & 6 & 6 \\
\hline Liczba doniczek & 5 & 5 & 5 & 5 \\
\hline
\end{tabular}

Objaśnienia: P - piasek podlewany wodą wodociągową, PA - piasek podlewany wodą wodociągową zawierającą archebakterie, $\mathrm{P}+\mathrm{S}$ - mieszanina piasku i dodatku substratu jonitowego podlewana wodą wodociągową, $\mathrm{P}+\mathrm{SA}$ - mieszanina piasku i dodatku substratu jonitowego podlewana wodą wodociągową zawierającą archebakterie. 


\section{Wyniki i dyskusja}

Uzyskane wyniki badań przedstawiono na rysunkach 1-4. Dodatek substratu jonitowego do piasku korzystnie wpłynął na proces wzrostu i rozwoju roślin istotnie zwiększając wartości parametrów wegetacyjnych. Świeża biomasa pędów uzyskana na podłożach $\mathrm{z}$ dodatkiem substratu jonitowego (serie $\mathrm{P}+\mathrm{S}$ i $\mathrm{P}+\mathrm{SA}$ ) była prawie 30-krotnie większa niż w seriach kontrolnych (P i PA) - rys. 1. Sucha biomasa pędów kupkówki rosnącej na piasku wzbogaconym w dodatek substratu (z i bez archebakterii) przewyższała suchą biomasę pędów roślin serii kontrolnych o ponad 20 razy (rys. 2). Świeża i sucha biomasa korzeni uzyskana w seriach $\mathrm{P}+\mathrm{S}$ i $\mathrm{P}+\mathrm{SA}$ była, odpowiednio: ponad 8-krotnie i ponad 6-krotnie większa niż w seriach kontrolnych P i PA (rys. 3 i 4). Wielkości parametrów wegetacyjnych tj. świeżej i suchej biomasy pędów oraz korzeni roślin rosnących na piasku podlewanym wodą wodociągową o odpowiednio: $10 \%, 11 \%, 7 \%$ i $15 \%$ przewyższały świeżą i suchą biomasę pędów oraz korzeni uzyskaną w serii PA, gdzie do podlewania roślin stosowano wodę wzbogaconą w archebakterie, aczkolwiek tylko w przypadku suchej biomasy korzeni różnica miedzy porównywanymi seriami była statystycznie istotna (rys. 1-4). Podobna tendencja zaistniała dla serii $\mathrm{z}$ dodatkiem substratu jonitowego bez i z wprowadzanymi archebakteriami. Wielkości świeżej i suchej biomasy pędów oraz korzeni kupkówki rosnącej w serii $\mathrm{P}+\mathrm{S}$ były większe w porównaniu do analogicznych parametrów uzyskanych w serii $\mathrm{P}+\mathrm{SA}$ o nie więcej niż 7\%, przy czym stwierdzone różnice nie były statystycznie istotne (rys. 1-4). Wbrew oczekiwaniom nie zaobserwowano zatem pozytywnego oddziaływania drobnoustrojów z domeny Archeae na proces wegetacji gatunku testowego. Oczekiwania te wynikały z informacji podawanych przez producenta preparatu Arkea ${ }^{\circledR}$ o potencjalnych mechanizmach pozytywnego oddziaływania drobnoustrojów z domeny Archeae na rośliny, obejmujących m.in. produkcję przez drobnoustroje substancji intensyfikujących wzrost roślin, czy degradację związków wydzielanych przez rośliny, które działają allelopatycznie lub autotoksycznie.

Uzyskane przyrosty biomasy roślin po wprowadzeniu testowanego substratu jonitowego do piasku potwierdziły wcześniejsze obserwacje dotyczące skuteczności stosowania tego typu materiałów jako nośników pierwiastków odżywczych dla roślin. Przykładowo badania Chomczyńskiej [20] wykazały, że substrat Mp przygotowany z poużytkowych żywic jonowymiennych i wprowadzony do jałowego piasku spowodował ponad 5,5-krotny przyrost suchej biomasy pędów i prawie 4-krotny przyrost suchej biomasy korzeni roślin. W innych badaniach prowadzonych przez Wasąga i współpracowników [21] stwierdzono, iż dodatek substratu Biona ${ }^{\circledR}-111$ do podłoża piaskowego zwiększył suchą biomasę pędów o ponad $1000 \%$ a suchą biomasę korzeni roślin o ponad $500 \%$. 


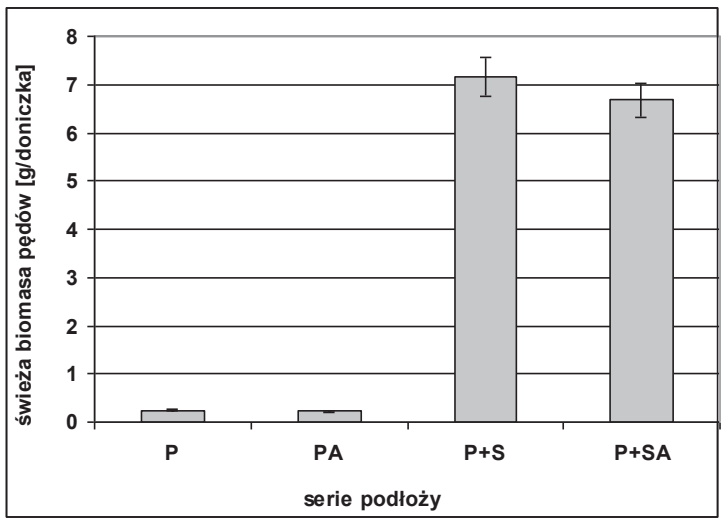

Rys. 1. Średnia świeża biomasa pędów kupkówki pospolitej w seriach doświadczenia wegetacyjnego. Średnie świeże biomasy pędów $\mathrm{w}$ seriach $\mathrm{P}+\mathrm{S}$ i $\mathrm{P}+\mathrm{SA}$ różnią się istotnie od średnich świeżych biomas pędów w seriach P i PA; I - odchylenie standardowe

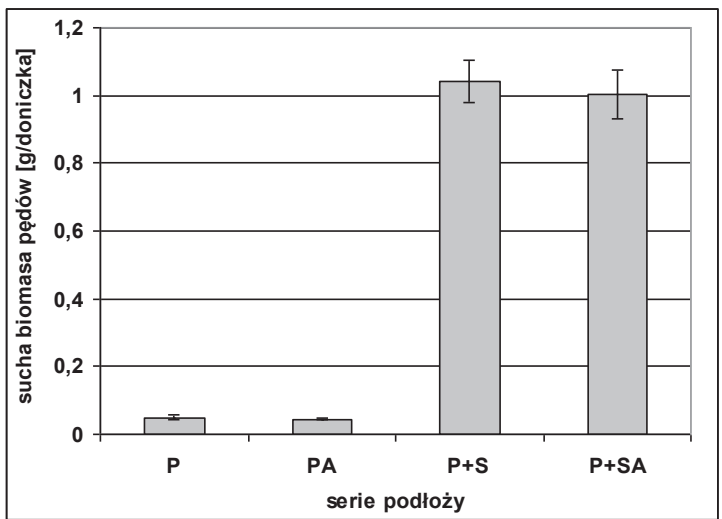

Rys. 2. Średnia sucha biomasa pędów kupkówki pospolitej w seriach doświadczenia wegetacyjnego. Średnie suche biomasy pędów w seriach P+S i P+SA różnią się istotnie od średnich suchych biomas pędów w seriach P i PA; I - odchylenie standardowe

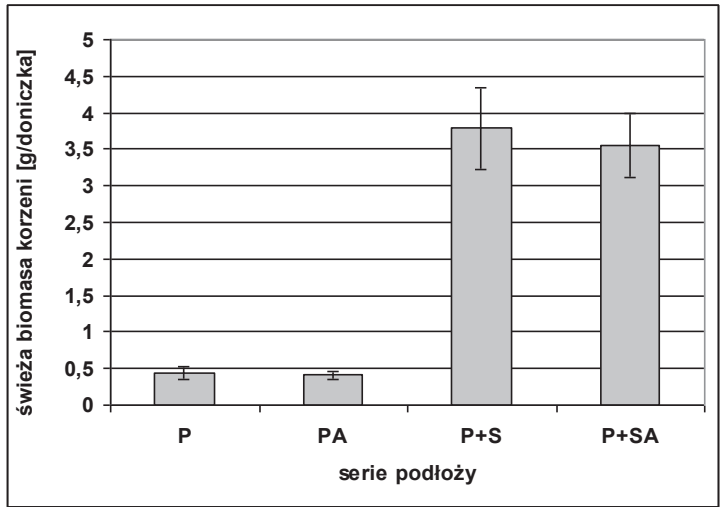

Rys. 3. Średnia świeża biomasa korzeni kupkówki pospolitej w seriach doświadczenia wegetacyjnego. Średnie świeże biomasy korzeni w seriach $\mathrm{P}+\mathrm{S}$ i $\mathrm{P}+\mathrm{SA}$ różnią się istotnie od średnich świeżych biomas korzeni w seriach P i PA; I - odchylenie standardowe 


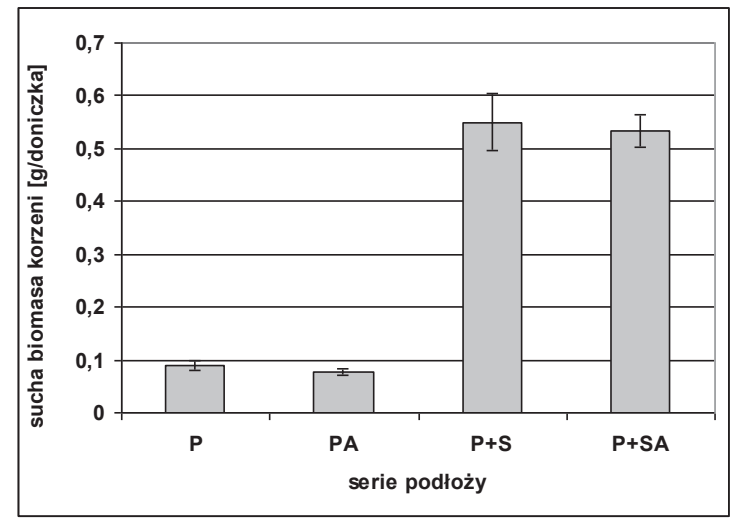

Rys. 4. Średnia sucha biomasa korzeni kupkówki pospolitej w seriach doświadczenia wegetacyjnego. Średnie suche biomasy korzeni w seriach $\mathrm{P}+\mathrm{S}$ i $\mathrm{P}+\mathrm{SA}$ różnią się istotnie od średnich suchych biomas korzeni w seriach P i PA; średnia sucha biomasa korzeni w serii P różni się istotnie od suchej biomasy korzeni w serii PA; I - odchylenie standardowe

\section{Wnioski}

Wyniki przeprowadzonych badań pozwoliły na sformułowanie następujących wniosków:

- Testowany substrat jonitowy jest skutecznym dodatkiem nawozowym istotnie zwiększającym biomasę kupkówki pospolitej.

- W warunkach eksperymentu mikroorganizmy z domeny Archeae nie wykazują pozytywnego oddziaływania na proces wegetacji gatunku testowego.

- Substraty jonitowe można polecić jako materiały intensyfikujące rozwój pokrywy roślinnej działającej stabilizująco i poprawiającej estetykę na terenach zdegradowanych i obiektach infrastruktury drogowej.

\section{Literatura}

1. Arnon D.I., Grossenbacher K.A. Nutrient culture of crops with the use of synthetic ionexchange materials. Soil Science 63 (1947) 159-182.

2. Soldatov V.S., Peryskina H.G., Horoshko R.P. Ionitovyje pocvy. Nauka i Technika, 1978.

3. Soldatov V.S., Peryskina H.G. Iskusstvennye pocvy dlja rastenij. Nauka i Technika, 1985.

4. Soldatov V.S., Pawłowski L., Szymańska M., Matusevich V.V., Chomczyńska M., Kloc E. Ion exchange substrate Biona-111 as an efficient mean of barren grounds fertilization and soils improvement. Zeszyty Problemowe Postępów Nauk Rolniczych 461 (1998) 425-436.

5. Sochan A., Bieganowski A., Ryżak M., Dobrowolski R., Bartmiński, P. Comparison of soil texture determined by two dispersion units of Mastersizer 2000. International Agrophysics 26 (2012) 99-102.

6. Ryżak M., Bartmiński P., Bieganowski A. Metody wyznaczania rozkładu granulometrycznego gleb mineralnych. Acta Agrophysica. Rozprawy i Monografie 4 (2009) 1-84.

7. Polska Norma, PN-R-04023: 1996. Analiza chemiczno-rolnicza gleby. Oznaczanie zawartości przyswajalnego fosforu $w$ glebach mineralnych.

8. Polska Norma PN-R-04022: 1996. Analiza chemiczno-rolnicza gleby. Oznaczanie zawartości przyswajalnego potasu $w$ glebach mineralnych.

9. Polska Norma PN-R-04021: 1994. Analiza chemiczno-rolnicza gleby. Oznaczanie zawartości przyswajalnego żelaza. 
10. Polska Norma PN-R-04020:1994. Analiza chemiczno-rolnicza gleby. Oznaczanie zawartości przyswajalnego magnezu.

11. Polska Norma PN-93/R-04019. Analiza chemiczno-rolnicza gleby. Oznaczanie zawartości przyswajalnego manganu.

12. Polska Norma PN-93/R-04018. Analiza chemiczno-rolnicza gleby. Oznaczanie zawartości przyswajalnego boru.

13. Polska Norma PN-92/R-04017. Analiza chemiczno-rolnicza gleby. Oznaczanie zawartości przyswajalnej miedzi.

14. Polska Norma PN-92/R-04016. Analiza chemiczno-rolnicza gleby. Oznaczanie zawartości przyswajalnego cynku.

15. Sady W. Nawożenie warzyw polowych. Wydawnictwo Plantpress, 2000.

16. Motowicka-Terlak T., Terlak H., Witek T. Liczby graniczne do wyceny zawartości siarki w glebach i roślinach. Seria (P). IUNG Puławy, 1993.

17. Kacperska I., Oświęcimski W., Przeradzki D., Stojanowska J. Opracowanie zaleceń nawozowych w ogrodnictwie. Wydawnictwo SGGW, 2002.

18. Czermiński J.B., Iwaszewicz A., Paszek Z., Sikorski A. Metody statystyczne dla chemików. PWN, 1992.

19. Zgirski A., Gondko R. Obliczenia biochemiczne. PWN, 1998.

20. Chomczyńska M. Utylizacja zużytych jonitów do rekultywacji zdegradowanych utworów piaszczystych - badania modelowe. Monografie Komitetu Inżynierii Środowiska PAN 3 (2001) $1-112$.

21. Wasąg H., Pawłowski L., Soldatov V.S., Szymańska M., Chomczyńska M., Kołodyńska M., Ostrowski J., Rut B., Skwarek A., Młodawska G. Rekultywacja zdegradowanych gleb przez zastosowanie żywic jonowymiennych. Raport. Politechnika Lubelska, 2000.

\title{
Application of ion exchange substrate and Archaea organisms for enhanced plant development on barren grounds
}

\author{
Mariola Chomezyńska ${ }^{1}$, Vladimir Soldatov ${ }^{2}$ \\ ${ }^{1}$ Faculty of Environmental Engineering, Lublin University of Technology, \\ e-mail:m.chomczynska@wis.pol.lublin.pl \\ ${ }^{2}$ Institute of Physical Organic Chemistry, Belarus National Academy of Science, \\ e-mail: Soldatov@ifoch.bas-net.by
}

\begin{abstract}
The study was carried out to test the ability of improving plant growth by ion exchange substrate and Archaea microorganisms on barren grounds (e.g. on road ambankments, bridge slopes). To achieve this aim, a pot experiment with orchard grass (Dactylis glomerata L.) as the test species was performed. For the needs of the test two media series were prepared: the control - sand (model of barren ground) and mixture of sand with $2 \% \mathrm{v} / \mathrm{v}$ addition of ion exchange substrate (carrier of nutrients for plants). During plant growth half of the pots in the control series was watered with tap water while the other half was watered with tap water enriched with Archaea organisms eluted from Arkea ${ }^{\circledR}$ substrate (the product of Archaea Solutions ${ }^{\mathrm{TM}}$ ). Pots containing the mixture of sand with ion exchange substrate were treated in the same way. After finishing the experiment, it was stated that the addition of ion exchange substrate to sand affected plat growth advantageously increasing values of vegetative parameters significantly. Contrary to expectation, the
\end{abstract}


positive effect of Archaea microorganisms on growth of test species was not observed. The ion exchange substrate can be recommended as mean improving plant development on degraded soils and road infrastructure facilities.

Keywords: ion exchange substrate, Archaea organisms, road infrastructure facilities. 